\title{
Feature Checking meets the Criterion Approach Three ways of saying only in Romance and Germanic
}

\author{
Josef Bayer \& Alexander Grosu
}

\section{Introduction \\ 1.1. Background}

The received wisdom within the version of Generative Grammar known as the Theory of Government \& Binding was that a quantified nominal whose 'understood' scope properties do not correspond to its overt position may achieve a suitable scope position through covert movement, specifically, through the application of a process known as Q(uantifier) R(aising). This position, which was vigorously advocated in May (1977, 1985), came under attack at the end of the eighties from scholars who either argued against LF as a component of the grammar (e.g., Koster 1987, Lappin 1991) or else proposed that the process called 'QR' should be allowed to apply to quantified and non-quantified nominals alike (Reinhart 1991). More recent developments in linguistic theory, in particular, the version of the Minimalist Program in Chomsky (1995), led to an even more radically modified view of LF. On the one hand, covert phrasal movement, and more generally, covert raising of a category (i.e., covert Move-a) was ruled out in general as uneconomical, Move-a, as well as phrasal PiedPiping, being licensed only in the overt component by the need to ensure 'convergence' at the PF interface. On the other hand, Minimalism allows a new kind of process, the raising of features. Importantly, neither phrases nor features can raise in order to ensure interpretability, but only in order to prevent a 'crash' at one of the two 'interface levels.' This view is thus in sharp conflict with May (op. cit.); as Hornstein (1995) puts it, the minimalistic grammar of movement is 'semantically myopic.' In short, the primary movement process is the raising of a single feature, and the primary driving force behind this process is the need to check off uninterpretable features. Within Minimalism, there are two ways in which an 'interpretable' operator feature can achieve scope by raising: (a) if it happens to be matched with an uninterpretable feature on the target of movement and thus raises in order to check off the latter, or (b) if it is Pied-Piped by another feature of the lexical item to which it belongs. Option (b) is licensed by the (unavoidable, in Chomsky's view) stipulation that all the formal features of a lexical item are automatically 'dragged along' when one of them is 'attracted' by a target for checking purposes.

It needs to be stressed that the checking processes envisaged by Chomsky are different in spirit from the 'criteria' proposed in Rizzi (1991), although the two share an operational configuration, the Spec-Head configuration. Rizzi's criteria involve the matching of two interpretable features, and moreover allow an element endowed with such features to convey them to an underspecified recipient by what he calls 'dynamic agreement' (see his treatment of French direct questions). Nonetheless, the chasm between the two views may 
be less deep than it initially seems. We would like to suggest that 'strict' Minimalism can be modified to incorporate Rizzi's transmission mechanism without fundamentally altering its conceptual orientation, if it is acknowledged that not every type of movement is triggered by a 'suicidal' attractor. Assume, for example, that an XP is endowed with a feature which is [+int(erpretable)] but occupies a position in the phrase marker that does not allow it to be fully interpreted. If such objects reach the LF interface, they will induce a crash. To become fully interpretable, they need to move to a position which fills in the missing specification. Assume for concreteness that an operator Op in situ has a set of [+int] features one of which requires Op to have scope over an appropriate domain. Then we can say that a scope domain 'attracts' the features of Op. But attraction here is not exactly what it is in the standard cases, because the domain to which Op needs to raise is contentually defined, and - as already pointed out - this operation ultimately involves the matching of interpretable features. In short, the particular implementation of criteria a la Rizzi that we suggested above constitutes a limited extension of Minimalism which preserves the view that movement is licensed by the need to ensure convergence at the two interfaces, while allowing two types of features to achieve this goal: (a) [-int] features are attracted and seek to 'commit suicide', and (b) un(der)specified [+int] features, which seek to attain full interpretability. In short, it seems to us that a marriage of Chomsky's and Rizzi's views in the way just outlined makes conceptual sense, if it turns out to be empirically needed.

\subsection{Goal}

In this article, we pursue a number of interrelated theoretical and descriptive goals. On the descriptive side, we compare and contrast three distinct syntactic constructions with essentially the same semantic import, one of which has not, to the best of our knowledge, been carefully described in the earlier (at least, generative) literature so far. These are illustrated with synonymous Italian, English and Romanian examples in (1a)-(1c); for ease of reference, we will call such constructions (I), (II) and (III) respectively.

a. La sola Maria si e presentata

b. Only Mary showed up.

c. \{Singura Maria, Maria singura $\}$ s-a prezentat.

What distinguishes these constructions is that the force of only seen in (II) is conveyed by agreeing adjectives in (1a) and (1c), which are moreover DP-internal in the former and DPexternal in the latter (all these items are in boldface). Furthermore, (I)-(III) are increasingly constrained in their distribution in that order in ways that will be made explicit below. Finally, while some version of (II) seems to exist in all the languages with which we are familiar, (I) and (III) appear to be less common; out of the five languages we address in this study (English, French, German, Italian and Romanian), only French exhibits all three. 
On the theoretical side, we will propose a unifying analysis of (I)-(III) which derives their distributional properties from their featural make-up; in particular, we will argue that increasing distributional restrictions correlate with increasing 'deficiencies' in the F(ormal) F(eature) set of the boldfaced items in (1) (and their counterparts in other languages). A more general theoretical innovation that we will argue for, and which goes hand in hand with the already proposed (A) generalized version of Chomsky's checking-driven F-raising mechanism, which, recall, incorporates (A') Rizzi's semantics-oriented criteria, is that the grammar of movement must recognize two types of covert movement, with distinct properties. Bayer (1998) offers abundant empirical evidence for this distinction, and proposes to analyse it in terms of Move-F, which he views as a purely mechanical process of the Computational System dictated by the 'suicidal greed' of uninterpretable FFs, and Move-a, which he views as a semantically-oriented operation that resembles $\mathrm{QR}$, but differs from it in that it is not simply adjunction, but rather movement to the specifier of a (potential) projection headed by an operator feature which is also inherent in the phrase to be moved.

The remainder of this paper is organized as follows. In section 2.1., we illustrate the operation of mechanism (A) in a construction other than the three which form the focus of this paper, and the ability of operator FFs to spread across the boundaries of 'left-branch' islands. In sections 2.2. and 2.3., we discuss construction (I), showing how interpretable operator features can 'spread' within such domains as DP and PP, crossing, in the process, the (language-specific) island boundaries that separate a DP from its immediately containing PP, as well as a left-branch DP from its containing DP. -- In section 3., we argue that the spread of operator FFs is blocked in constructions of type (II) by the lack of categorial FFs in items like the boldfaced one in (1b). We will argue that the only way for such items to achieve scope wider than their overt position is to take part in 'long distance'movement, an operation reflected in sensitivity to prepositional and left-branch islands. -- In section 4., we show that constructions of type (III) are acceptable only if items like the boldfaced one in (1c) can acquire appropriate scope on the basis of their overt position. Covert F-spread or long-distance movement is ruled out by the assumption that the kind of items under consideration fail to make their operator FFs visible to the computational system

\section{Feature-spreading as a licensing factor}

\subsection{Spec-Head Agreement and c-command}

We begin by illustrating the workings of mechanism (A) -- in particular, of its (A') component -- in an unrelated construction, specifically, one where an operator feature originates within the Spec (of the Spec, etc.) of a DP that undergoes overt Pied-Piping.

Consider the English data in (2) and the parallel dialectal German data in (3).

(2) a. [Which student's mother's canary] did you poison?

b. [No student's mother's canary] have I ever poisoned.

a. [Welchem Studenten seiner Mutter ihren Kanarienvogel] hast du vergiftet? 
which student $t_{\mathrm{DAT}}$ his mother $_{\mathrm{DAT}}$ her canary ACC $_{\text {ave you poisoned }}$ 'Which student's mother's canary have you poisoned?'

b. [Keinem Studenten seiner Mutter ihren Kanarienvogel] habe ich je vergiftet.

no student ${ }_{\text {DAT }}$ his mother ${ }_{\text {DAT }}$ her canary have I ever poisoned

'No student's mother's canary have I ever poisoned.'

Observe that the features WH or NEG associated with the boldfaced items occur within the Spec of the Spec of the bracketed DP. These features are demonstrably responsible for a number of properties of these data, in particular, for the fact that the bracketed DPs in (2) occur in the leftmost position of a 'verb-second' (V2) configuration (something that is permitted in English only under special conditions), and the fact that negative polarity items are licensed within the VP, suggesting that the boldfaced items have scope over VP (see the (b) subcases of (2)-(3)). Importantly, not only are the boldfaced items necessary for the presence of such effects, but they moreover cannot induce them from just any position within a containing DP, as shown by the deviance of the data in (4).

(4) a. ?*[A canary that which student owned] did you poison?

b. *[A student with no canary] have I (ever) seen.

In short, the bracketed constituents in (2)-(3) induce the same effects as when the maximal DP is the minimal one that includes operators, as is the case, for example, in which/no canary.

In past literature, there have been a variety of attempts to analyse Pied-Piping and scope out of Spec effects, none of them fully satisfactory with respect to data like (2)-(3). For example, Safir (1986) suggested, with respect to a different Pied-Piping configuration (illustrated by the height of the lettering on the covers of which), that the minimal wh-DP undergoes (cyclic) extraction out of higher DPs and ultimately adjoins to the top DP; such an account does not obviously generalize to data like (2a), because which in the example just given can undergo long extraction out of DP, while left-branch items like those in (2a) cannot. Reinhart (1987) simply stipulated that specifiers (of specifiers) may bind in cases like (2)-(3). In her account, a DP in SpecDP carries a referential index and an operator index in order to distinguish anaphoric and variable binding. Nothing is assumed, however, about feature percolation and its consequences for Pied-Piping. Chomsky (1995) sketched an account of the obligatoriness of Pied-Piping in cases like (2a) which did not require the boldfaced item or its features to raise from their overt position, but his account does not obviously generalize to other instances of Pied-Piping, and does not offer a solution to the scope effects, either. What we want to show now is that the (A') component of mechanism (A) provides a straightforward account of both the Pied-Piping and the VP-scope effects in (2)-(3). To see this, consider the following (partial) representation of the top DP in (2a, b). 
(5)

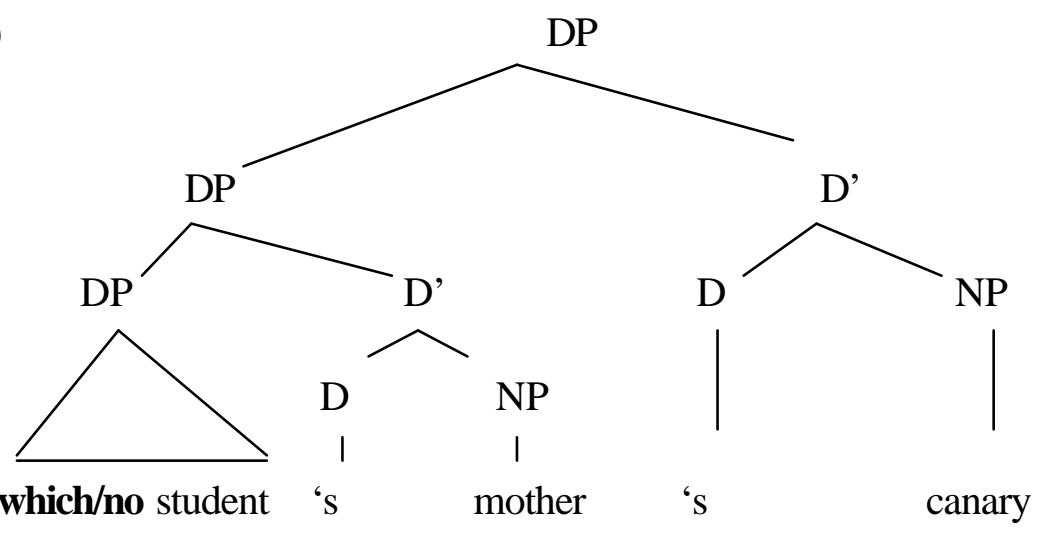

We have refrained from indicating the internal structure of the minimal DP because we do not wish to take a stand on whether the boldfaced item is under D or under SpecDP. If it is under $\mathrm{D}$, its operator properties automatically project to its maximal projection, that is, the minimal DP. If it is in SpecDP, we need to assume a null D with an unspecified operator feature that receives specification from the boldfaced item in SpecDP by mechanism (A'); this specification will automatically spread to DP. Now, if we make the further assumption that the possessive morpheme ' $s$ can be endowed with an unspecified operator feature, the transfer mechanism (A') will apply twice, ultimately ensuring that the operator features of the corresponding boldfaced item become properties of the maximal DP. We note that the sequence of operations we have sketched is applicable regardless of whether the phrases in SpecDP are base-generated in this position, or whether they are raised into it from SpecNP. -- Comparable operations may be assumed to take place in the derivations of ( $2 b$ ) and (3ab).

The fact that the maximal DP inherits the operator properties of the boldfaced items enables it to raise to the specifier of a suitable category ( $\mathrm{CP}$ or $\mathrm{NegP})$, and also ensures that polarity items within VP are c-commanded, and thus licensed, by an appropriate operator feature. Since the raising of DP to SpecCP or SpecNegP has automatic scope effects, it seems reasonable, given the (extended) (A)-type model we are assuming, to attribute this process to its (A') component. At the same time, the fact that this type of movement is overt requires an appeal to Chomsky's notion of 'featural strength', or some equivalent device that is not semantically-oriented. -- We do not claim that this is the only way in which these results can be achieved (for example, the theory in Kayne 1994 seems capable to achieve them in different ways), and we certainly do not claim to have a general theory of PiedPiping, which, to the best of our knowledge, nobody has (construction-specific and language-specific variation, as well as optionality under certain circumstances, remain largely unexplained). We do believe, however, that the Minimalist approach incremented with criteria offers a natural alternative to earlier stipulative accounts.

As has often been noted, the constructions in (2)-(3) are not obviously suitable for direct semantic intepretation, and there have been a variety of proposals to implement 'reconstruction.' It seems to us that the proposals in Chomsky (1993) offer a rather natural implementation. We remind the reader that the proposal under consideration assumes that 
A'-chains are generated with full copies of the moved phrase, and that such chains undergo independent deletion operations in both the PF and the LF portions of the derivation. The deletions on the branch of the derivation that end at LF are driven by the need to ensure interpretability by semantic operations. To illustrate, we indicate the material that needs to be deleted in $(6 a, b)$ to achieve a suitable input to semantics for (2a) and (2b) respectively. -With respect to (6b), we assume that the item no is 'split' into sentential negation and an existential quantifier, an operation that is needed independently of chain formation, and that may well be accomplished by post-LF purely semantic operations. ${ }^{1}$

(6) a. [Which dent's mother's student's mother's canary]

b. [No dent's sther's have I ever poisoned [ne student's mother's canary]

\subsection{Adnominal adjectival operators and feature spreading within DP}

Having illustrated the operation of the generalized (A) mechanism, we now turn to a closer examination of construction (I).

A number of languages allow agreeing elements with adjectival morphology that are internal to DP and induce a construal similar to the one that results from the combination of DP with only or its counterparts in other languages. We illustrate this state of affairs in (7) and (8) with data from Italian, French and German, noting that Romanian and English do not allow such constructions. These adjectives are invariably pre-nominal, even in French and Italian (where post-nominal APs are quite common; see Cinque 1993: 255f), and moreover do not allow (adverbial) modification of any kind; two properties that point to probable functional status. We provide data in which the containing DPs occur in both subject and object position with 'malice aforethought'; the precise reasons will become clear in section 4.

a. La sol -a Mariasi e presentata the alone-AGR Maria REFL is presented 'Only Mary showed up.'

b. La seul -e reine peut resoudre ce problème the alone-AGR queencan solve this problem

'Only the queen can solve this problem.'

c. Die alleinig-e Königin kann dieses Problem lösen the alone -AGR queen can this problem solve 'Only the queen can solve this problem.'

(8) a. Ritengo la sol -a regina la rappresentante vera consider-I the alone-AGR queen the representative true de-1 popolo 
of-the people

'I view only the queen as the true representative of the people.' 


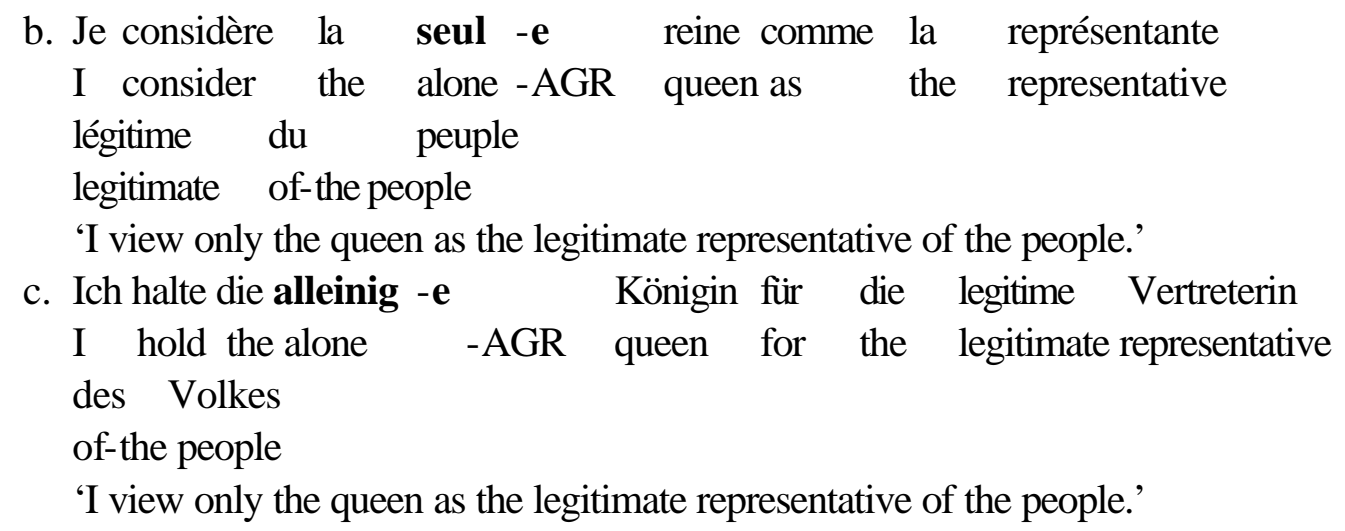

To avoid unclarity, we note that we have glossed the boldfaced items as 'alone' simply because they are typically homonymous in the corresponding languages with words that mean 'unaccompanied', 'unaided', or 'only' in phrases like the only girl he ever loved.

For completeness, we note that (I)-type constructions belong to a somewhat elevated register in Italian, French and German, and also that English and Romanian go one step further in disallowing such constructions altogether. For example, the data in (9)-(10) can at most have some of the meanings mentioned at the end of the preceding paragraph, but not the one that interests us here.

(9) a. The $\{$ sole, *alone $\}$ queen can solve this problem.

b. I view the $\{$ sole, *alone $\}$ queen as the legitimate representative of the nation.

a. Singur -a regin a va rezolva problem-a aceasta. alone -the-AGR queen will resolve problem-the this

'The queen, who is alone, will solve this problem.'

b. $\mathrm{O}$ consider pe singur- $\mathbf{a}$ regina drept reprezentant - $\mathrm{a}$ her consider-I ACC alone-the-AGR queen as representative -the legitima a poporu-1 -ui. legitimate of people-the-AGR -Gen-AGR

'I view the queen, who is alone, as the legitimate representative of the people.'

We will consider in section 4. how parametric variation involving such 'adjectival operators' can best be stated.

Let us now consider what the LF of data like those in (7)-(8) might look like. To the extent that the adjectives at issue have the essential import of 'only', they need to be construed as propositional operators (see Bayer, 1996 for detailed justification). To achieve this outcome, they must c-command (at least) the clause's C(omplete) F(unctional) $\mathrm{C}$ (omplex) in the sense of Chomsky (1986), that is to say, the verb and (the traces of) all its arguments (we will return to this point in subsequent sections). How can this result be achieved? We will argue that the following sequence of operations applies: (i) the operator feature spreads to DP, (ii) DP is covertly reordered to a scope position if it is not already in 
such a position, (iii) suitable 'tampering' with a chain that contains the operator leaves it in an appropriate scope position.

Step (i) is unproblematic, given (the (A') component of) (A). Cinque (1993) proposes that a variety of adnominal (adjectival) modifiers of $\mathrm{N}$ occur in the Spec of a number of well-defined functional projections, while leaving open the possibility that at least some of the items which do not exhibit demonstrably phrasal properties are in functional head positions. With respect to the kind of data in (7)-(8), we find the latter kind of analysis more plausible than its alternative, and will in fact assume it in what follows (note that semantically plausible adverbial modifiers of the adjective, such as French tout and German ganz 'completely', are decidedly out). Nonetheless, we outline the feature-spreading mechanism under both analyses.

Under the head analysis, the DPs in (7)-(8) have essentially the structure in (11) (we eschew the issue of the exact nature of the functional category by labeling it ' $\mathrm{W}(\mathrm{P})$ ', while noting that it must be able to license agreement between the adjective, the noun, and D).

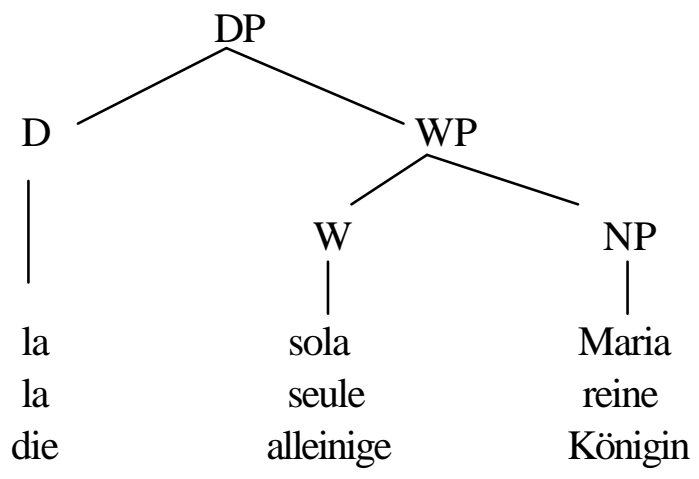

Grimshaw (1991) proposed that the functional categories of 'extended projections' agree with the lexical category in categorial features; for example, the lexical and functional categories of a nominal extended projection were all assumed to carry the features $[+\mathrm{N},-\mathrm{V}]$. One way of reconstructing this idea within a framework that employs feature checking is to assume that the noun carries an interpretable $\mathrm{N}$ (ominal) feature and that all the functional heads of its extended projection carry uninterpretable $\mathrm{N}$ features. This will force the $\mathrm{N}$ feature of the noun to raise covertly by successive adjunction operations to all the functional heads above it, checking off their uninterpretable features one by one. Since at each such step, the category that hosted an adjunct on the preceding step raises, too, the operator features of the adjective under W will raise to D, ultimately spreading to DP. ${ }^{2}$-- Under the Spec analysis, the head $\mathrm{W}$ is either empty or contains the adjectival suffix. In the spirit of Chomsky (1993; 1995), let us assume the former, which yields the structure in (12). 
(12)

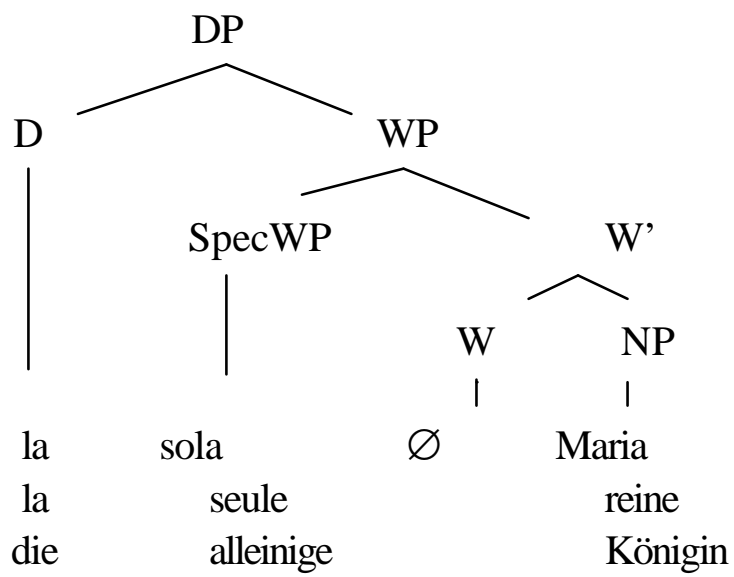

The null head $\mathrm{W}$ now carries, in addition to an uninterpretable $\mathrm{N}$-feature, an underspecified operator feature. In virtue of the mechanism (A') (dynamic agreement), the adjective specifies this feature, which, in virtue of Head-to-Head raising, will reach D and -- by transitivity -- ultimately DP.

Step (ii) is needed only in the derivation of (8). Provided that the surface subject is "high enough" to have scope over the CFC, the DP in (7) does not have to undergo further raising. Actually, the status of (7) warrants closer consideration because the overt presence of DP in a scope position does not automatically mean that the operator will take scope from that position. Thus, Bayer (1996) proposed that operators like the one under consideration cannot end up in just any position that guarantees clausal scope, but only in the Spec of a specific category, which he labelled 'PrtP' (Particle Phrase) and which, he argued, includes VP as a complement of its head. This view falls under the theory of quantification developed by Beghelli \& Stowell (1995), which proposes to account for relative operator scope in terms of the relative hierarchical height of functional projections, and which has also proven beneficial for the characterization of the linear order of operators in languages where linear order reflects relative scope, such as Hungarian (Kiss, 1991; Szabolcsi 1995). Note that, under the assumption that VP is a complement of Prt, PrtP is the hierarchically 'lowest' of the scope-oriented functional categories. We note that, according to Bayer (1996), the DP in data like (7) is not itself in SpecPrt, but one of the copies that it created in raising from SpecVP is. What is needed, then, in order to achieve an interpretable LF is the application of step (iii), and in the following way: everything but the operator must be deleted from the copy in SpecPrtP, nothing but the operator must be deleted in the lowest copy, and any additional copies must be entirely deleted. ${ }^{3}$

In the derivation of data like those in (8), step (ii) is unquestionably necessary, since DP is clearly not in a clausal scope position in overt representation. Note, however, that step (ii) is inconsistent with the hypothesis advanced in Chomsky (1995) to the effect that all covert movement is Move-F. Consistency with this hypothesis could only be achieved, if the operator features (together with the remaining FFs) raise and adjoin to Prt; although it must be stressed that Move-F is supposed to fall outside the known processes of categorial 
movement, such a process would perhaps resemble head movement more than phrasal movement (cf. Brody, 1998: 382). Bayer (1996: 57-59) presents a number of arguments against scoping of Prt by head movement. To the extent that head movement equals MoveF plus Pied-Piping of the minimal morphological carrier (perhaps a phonological word), these arguments apply to Move-F as well. While Move-F would immediately allow operator features to reach a proper scope position, this implementation of step (iii) seems to be all too easy. We return to the issue of the choice between analyzing QR as Move-a or Move-F in section 3.

\subsection{Feature Spreading from DP into PP}

We now turn to DPs which, just like those in (8), fail to be in scope position in overt representation, but which, unlike those in (8), are complements of a P. These data provide an indication of the kind of factors that could in principle adjudicate between feature raising and phrasal raising for scope assignment (see comments on step (ii) in the preceding section), but in actual fact, no decision is yet possible, for reasons that will become apparent below.

Consider the data in (13a-c), and note that the boldfaced items have the same force as those in (7)-(8). For completeness, we add the superficially similar Romanian datum in (13d), which, just like (10), disallows this kind of construal for the boldfaced adjective.

(13) a. Il re ha parlato [PP con [DP la the king has spoken with the alone-AGR queen

'The king has spoken only with the queen.'

b. On ne peut plus compter [PP sur [DP one not can more rely on the alone -AGR queen 'One can no longer rely only on the queen.'

c. Man kann sich nicht [PP auf [DP die alleinig-e Königin verlassen] one can REFL not on the alone-AGR queen rely 'One cannot rely only on the queen.'

d. Nu se mai poate conta [pe [ singur-a regina] not REFL more can rely on alone-the-AGR queen 'It is no longer possible to rely on the queen, who is alone.'

Assuming that the operator features of the boldfaced adjectives reach the containing DP by the mechanisms discussed in the preceding section, we are now faced with a potentially surprising result: On the one hand, we may expect DP to move to SpecPrtP (or its operator and remaining FFs to move to Prt), just as in the derivation of (8). On the other hand, we may expect -- given the very reasonable assumption made in Chomsky (1993) to the effect that constraints on movement are insensitive to the overt/covert status of movement -- that the data in (13a-c) should be deviant, because overt movement cannot strand Ps in the 
corresponding languages. That the data at issue are not deviant points to the conclusion that the PP 'island' boundary is circumvented in some way.

The solution we wish to propose was suggested to us by a comparable, if weaker, contrast found in relation to left-branch constituents. While the left-branch constraint on overt extraction is weaker in German data like (3) than in English data like (2) (presumably, because neither the stranding of an affix nor the reordering of a non-constituent are involved; see Chomsky 1995: 263), most speakers nevertheless witness a clear effect, as illustrated in (14a-b). But such an effect is absent in comparable type-(I) constructions, as illustrated in $(14 c)$.

(14) a. [[Welchem Studenten] seine Ansichten] meinst du, seien which ${ }_{\mathrm{DAT}}$ student his views think you are SUBJ berïcksichtigt worden? taken-seriously become

'Which student's views do you think were taken seriously?'

b. ??[Welchem Studenten] meinst du, [ $\mathrm{t}$ seine Ansichten] seien berücksichtigt worden?

c. [[Dem alleinigen König] seine Ansichten] sind berücksichtigt worden. the $e_{\text {DAT }}$ alone king his views are taken-seriously become 'Only the KING's views were taken seriously.'

The contrast between (14b) and (14c) is unsurprising, in view of what was said in section 2.1 about the data in (2)-(5): the operator FF in (14c) can spread to the largest containing DP by exactly the kind of local steps that were posited for (2)-(3), thus circumventing the need to violate the left-branch constraints of German. What we want to suggest is that a similar tack is possible with respect to the data in (13a-c). Thus, a number of writers have provided evidence that Ps function in certain respects very much like alternative realizations of Case. For example, Grosu (1994) shows that affixal Case and Ps function in the same way with respect to a variety of matching and non-matching effects in relative clause constructions of various kinds. Gallman $(1996,1997)$ shows that certain German vocabulary items that fail to exhibit overt Case inflection, for example, nichts ('nothing'), may not occur in environments where some oblique Case, in particular, Dative, is required (see (15a)). Nonetheless, this item can occur as complement of the P mit, which requires precisely dative Case, as illustrated in (15b). Grosu (1994) provides extensive evidence that in German and various other Indo-European languages, Ps always count as oblique Case for the purpose of the (non)-matching effects he studied. All this suggests that in (15b), P satisfies a requirement that is violated in (15a), namely, that items like nichts needs to exhibit some oblique Case morphology in oblique contexts.

(15) a. *Peter hat nichts widersprochen.

Peter has nothing objected

'Peter has objected *(to) nothing.' 
b. Peter ist mit nichts zufrieden.

Peter is with nothing satisfied

'Peter is satisfied with nothing.'

Now, if Ps can function as alternative realizations of Case in situations like those just described, it seems reasonable to assume that they function as realizations of Case in other respects as well, in particular, in further extending an extended nominal projection. If so, we may assume that Ps are, or at least can be, endowed with an uninterpretable $\mathrm{N}$ feature, with the result that the $\mathrm{N}$-feature that has raised as far as $\mathrm{D}(\mathrm{P})$ will further raise to $\mathrm{P}$, and ultimately spread to PP. The assumption of $\mathrm{N}$-feature movement to $\mathrm{P}$ has a clear advantage. Being independently motivated, it explains why PPs are transparent to certain kinds of processes, a fact that has caused various researchers to propose unconventional accounts. ${ }^{4}$

\section{Particle Operators}

We now turn to constructions of type (II). As already noted in section 2.2, items with the semantic force of only need to be construed as propositional operators. Bayer (1996) argues that this construal can sometimes be straightforwardly derived from the overt representation, in particular, when this particle is base-generated in the head position Prt, as seems to be the case in (16). Bayer also observes that there are other situations where the needed construal is not obviously derivable in this way, because the particle appears to form a constituent with constituents smaller than VP, for example, with subjects, objects or PPs. Data that point to this conclusion are provided in (17). Observe that the proposed constituent [only XP] occurs in the first position of what is plausibly a V2-construction in (17b), and in the focus position of a cleft construction in (17c)), two positions that have been widely regarded as reliable diagnostics for constituency.

(16) John can [only [play the piano]

(17) a. John can play [only [the piano]].

b. [Only [the piano]] can John play.

c. It's [only [by working hard]] that we will ever achieve anything.

Now, under the view that the strings within the more inclusive sets of brackets in (17a-c) form constituents, additional already familiar covert operations will need to apply. In (17a), for example, covert raising is unavoidable. ${ }^{5}$ Just as in the cases we examined in sections 2.2 and 2.3, we are faced with the dilemma of whether this operation constitutes feature raising to Prt, or phrasal raising to SpecPrt followed by selective deletion in the resulting chain.

Now, consider (18a-c), which are essentially synonymous with (13a-c) respectively, and compare them with the corresponding subcases of (19); for completeness, we have added 
Romanian examples in (18d) and (19d), since Romanian does have the kind of construction under consideration here.

(18) a. Il re ha parlato solo con la regina. the king has spoken only with the queen 'The king has spoken only with the queen.'

b. On ne peut plus compter seulement sur la reine. one not can more rely only on the queen 'One can no longer rely only on the queen.'

c. Man kann sich nicht nur auf die Königin verlassen. one can REFL not only on the queen rely 'One cannot rely only on the queen.'

d. $\mathrm{Nu}$ se mai poate conta numai pe regina. ${ }^{6}$ not REFL more can rely only on queen 'It is no longer possible to rely only on the queen.'

(19) a. *Il re ha parlato con solo la regina.

b. *On ne peut plus compter sur seulement la reine.

c. *Man kann sich nicht auf nur die Königin verlassen.

d. *Nu se mai poate conta pe numai regina.

The only observable difference between (18) and (19) is that only is attached to a PP in the former and to the DP complement of $\mathrm{P}$ in the latter, so this difference must be somehow responsible for the contrast in acceptability between the two sets of data. What we want to suggest, following Bayer (1996), is that the operator features of only, in contrast to the operator features of the kind of adjectives we studied in sections 2.2 and 2.3, are unable to spread 'upwards' beyond their overt position for reasons that we will make explicit below. If so, in data like (19), either the complement of $\mathrm{P}$ or its operator features must raise directly to SpecPrtP or Prt respectively. Note that the unacceptability of the data in (19) parallel the unacceptability of P-stranding in the corresponding languages. -- In contrast to Italian, French, German and Romanian, P-stranding is possible in English, and -- correlatively -data like (19) are also possible. To be entirely accurate, some speakers of English prefer data of the form shown in (18) to data of the form in (19), but data of the former kind are nonetheless often used in English, while in German, French, Italian and Romanian, they do not seem to be ever used. ${ }^{7}$ In support of the claim just made, we offer a sample of attested English data parallel to (19); these have appeared in print, and thus cannot be dismissed as mere 'speech errors'.

(20) a. George Lakoff has pointed out to me that on the basis [of [only the facts considered so far]], it would be unnecessary to state the Sentential 
Subject Constraint ... (J.R. Ross, 1974)

b. ... syntactically appropriate [to [only the non-preferred reading of the ambiguity]] (P. Gorrell, 1987) 
c. It has scope [over [only the matrix-clause element it binds]]

(A. Davison, 1988)

d. The computation "looks [at" [only F and a sublable of K]]

(N. Chomsky, 1995)

Another set of data where restrictions on scope parallel restrictions on extraction is found with left-branch constituents. Consider the data in (21)-(22).

(21) a. Which student's canary did you poison?

b. *Which student's did you poison canary?

(22) a. (?)[[JOHN's canary] only] have I poisoned.

b. *[\{[JOHN's only], [JOHN only]'s $\}$ canary] have I poisoned.

While for various speakers (22a) may suffer from the postposition of only -- witness that the test cannot be made with focus-preceding only --, the example seems to be clearly better than those in (22b). We will consider the (possible) implications of the facts in (18)-(22) after making a proposal on the factors which, in our view, block the upwards spread by local steps of the operator features of the boldfaced items.

According to Bayer (1996), particles such as only cannot acquire categorial status unless they appear in a potential scope position, which, in core cases like (13), is a sister to VP. ${ }^{8}$ The reason for this is that particles -- in contrast to functional elements such as D and C -lack inherent syntactic categorial features, an assumption that is motivated by their highly promiscuous behaviour, that is, by their ability to combine with virtually any potentially phrasal category. Building on an idea in Rothstein (1991), one may say that only is a 'minor' functional category, that is, a category that has no categorial FFs to project, but only semantically-oriented ones. As far as their external syntax goes, phrases of the form [Prt $\mathrm{XP}]$ or [XP Prt] have the essential distribution of XP. Within the framework we proposed in section 1.1, we can express this state of affairs by assuming that Prt has a completely unspecified interpretable categorial feature, which needs to derive its specification from the categorial FFs of XP; if we furthermore assume that the unspecified categorial FF of Prt can optionally be strong, we can account for [XP Prt] orders by assuming overt raising of XP to the particle's specifier. -- Now, just as a +wh DP or a +neg QP fails to be a question or a negative statement all by itself, [Prt DP] does not amount to a focus construction all by itself. The operator feature inherent in Prt can only play a role in the semantics, and this is only possible if a suitable scope position has been reached. Thus, a 'PrtP' is a phrase headed by an operator feature inherent in Prt. According to this reasoning, [only [the piano] in $(17 \mathrm{a}, \mathrm{b})$ is simply a DP with an unlicensed operator feature, while [only [play the piano] in (16) is categorially a VP and semantically a PrtP in virtue of the fact that the operator feature inherent in Prt can now have appropriate scope. 
Morphologically, particles are invariant elements, that is, elements which lack an inflectional paradigm altogether. From the perspective of Grimshaw (1991), only cannot even abstractly 'agree' in categorial features with $\mathrm{N}$, since it has no categorial features (by assumption). Translated into a feature-checking framework, this generalization takes the following form: only lacks not only inherent (interpretable) categorial features, but also uninterpretable categorial features. When combining with a DP, it cannot attract the interpretable $\mathrm{N}$-feature that has raised to $\mathrm{D}$, so that in cases like (19), $\mathrm{D}+\mathrm{N}$ can in principle raise to $\mathrm{P}$ only directly, without adjoining to only. If so, the operator feature of only is unable to get a 'free ride' on an independent raising process, and thus cannot reach $\mathrm{P}(\mathrm{P})$. The operator feature of the particle will then reach the conceptual-semantic interface without being able to attain a suitable scope position, and the derivation will crash due to a violation of the Principle of Full Interpretation (Chomsky 1986).

Let us now return to the parallelism between restrictions on overt movement and restrictions on the scope of particles that were noted in connection with (18)-(22), and let us address it in conjunction with the effects reported on in Bayer $(1998 ; 1999)$ which we already alluded to in section 1.2. Given Chomsky's (1993) hypothesis that constraints on movement apply in both the overt and the covert mode, the parallelism just noted points to the conclusion that (18)-(20) and (22) involve long distance covert movement. Bayer (1998) observes that some speakers find (16) with focus on the piano more felicitous than (17a). The difference is subtle and seems to be more pronounced in pairs such as They didn't call any student at home and They called no student at home. As also reported there, preliminary experimental work using speeded grammaticality judgements and the selfpaced reading technique suggests that comparable distinctions are reflected in on-line comprehension. This ties in with the conclusion that QR is a 'marked' operation. Reinhart $(1993 ; 1997)$ and Fox $(1994 ; 1995)$ urge, on the basis of different data, the even stronger conclusion that $\mathrm{QR}$ is permitted just in case it yields a reading that is not attainable without movement; unless further qualifications are added, this position would make the factually incorrect prediction that data like (17a) are out, since, given that focus is confined to the phrase the piano, (16) achieves a non-distinct reading without movement. Be this as it may, what matters for our purposes is that data that involve QR have a more or less marked status, and thus stand in contrast with data in which covert operations on features have either no semantic import or no semantic motivation; an illustration of the former is provided by English sentences without auxiliaries, where, according to Chomsky (1995), V-features covertly raise to T(ense) and Agr; illustrations of the latter involve feature percolation in DP and PP as already discussed. Bayer (1998) sought to account for the distinct status of the two kinds of processes by taking the position that processes like V-Raising in English and percolations of the sort described above are instances of FF-Raising (i.e., Move-F with Pied-Piping of the remaining FFs), while QR is an instance of phrasal raising. Let us point out, however, that with respect to the assumptions about bare phrase structure and covert movement, the term "phrasal movement" may be misleading from the outset. If Greed-driven covert movement is semantically motivated, the element to be moved is an amalgamation of [+int] features, not a morphosyntactic entity such as a DP or a PP. The question is then how 
much will be moved covertly at a time. Chomsky suggests that it is a single feature that may under certain conditions Pied-Pipe other features. We feel, however, that this issue has to be resolved empirically. There is, for example evidence that covert movement may undo Principle-C effects. ${ }^{9}$

If so, a plausible reason may be that the semantic structure to be raised can involve more than simply the feature that heads the QP. Seen from this perspective, covert movement of an operator may be the movement of a [+int] feature that can carry along other [+int] features, essentially giving rise to LF Pied-Piping. The gist of the proposal in section 1.1. was, recall, that both non-semantically and semantically oriented operations on features can be analyzed as driven by the need to ensure convergence at the LF interface, although this goal is achieved in distinct ways. Now, the data in (2)-(3), which we analyzed in terms of the semantically oriented mechanism (A'), do not have the marked status of QR constructions. The crucial difference between the two kinds of situation in which mechanism (A') is activated is that in (2)-(3), the configuration needed for activating it is achieved in virtue of Merge, while in data with $\mathrm{QR}$, a suitable configuration can only be achieved by a self-propelled operation of Move. The constructions with marked/unmarked status can then be characterized as follows: Operations dictated by the need to eliminate [-int] features, or by the need to identify un(der)specified interpretable features in configurations created by Merge, are unmarked; operations of the latter kind that also appeal to Move are marked. -To avoid any possible confusion, we hasten to stress that we do not predict marked status for just any construction in which phrases have wider scope than their overt position, but only for those that must resort to QR; for some discussion of wide-scope effects that can circumvent appeals to QR, see, e.g., Tsai (1994) and Reinhart (1997).

In conclusion, we propose the (A) mechanism as an operation which is entirely driven by non-semantic forces but enables semantically relevant formal features such as operator features to surface in places which do not count as islands in spite of their morphophonological locatedness in the string; we propose in addition an (A') process of covert movement which is entirely driven by semantic forces. This latter process comes close to the familiar QR-style movement but -- given the Minimalist reinterpretation of linguistic theory -- must be seen somewhat differently. Two aspects are relevant: (a) it can be naturally integrated into the spec-head agreement mechanism of the criterion approach; the earlier adjunction approach can perhaps entirely be dispensed with, at least if the Beghelli \& Stowell approach proves to be equivalent; (b) self-propelled covert movement may be movement of [+int] features, but there is no necessity of assuming with Chomsky that it is nothing but the movement of a single feature. To the extent that it makes any sense to speak of covert XP-movement, i.e. movement of the semantic side of XP, we concede that covert movement may also be covert Move- $\forall$. We think this will do as much harm as taking Move-F as covert head movement. As far as we can see, whatever account of language-specific P-stranding options is assumed can be extended to data like (19)-(20) regardless of whether the displacement process affects phrases or just FFs. As for the deviance of (22b), it can be attributed either to the fact that QR purports to reorder a non- 
constituent (i.e., to the factor which, according to Chomsky (1995: 263), blocks data like (21b)), or to the fact that only purports to combine with a non-constituent

\section{DP-external adjectives}

We now turn to constructions of type (III). These are found in French and Romanian, but not in Italian, and despite initial appearances to the contrary, they do not exist in English or German either. Descriptively, they exhibit the same kind of agreeing, non-modifiable 'adjectives' with operator import as constructions of type (I), with the notable distinction that these adjectives sit outside DP, rather than within it. Just like the non-agreeing particles discussed in section 3, they can in principle either precede or follow DP, subject to certain conditions of 'relative heaviness' that will be made explicit below. We provide a first illustration of type-(III) constructions in (23), using both French and Romanian data.
a. Seul -e la reine / la reine seul-e peut encore nous aider alone-SG-F the queen can still us help 'Only the queen can still help us.'
b. Singur-| regin-| / regin| singur-| ne mai poate ajuta. alone-SG-F queen-DEF-SG-F us still can help 'Only the queen can still help us.'

While (III)-type constructions have remarkably parallel properties in both languages, we will use data from both languages in what follows, and this, because each language sheds light on certain aspects about which the other is silent. Thus, the fact that the adjective agrees with DP in number and gender is only orthographically detectable in French, but in Romanian, it is phonologically detectable as well. At the same time, French has cleft and complex inversion constructions, which Romanian lacks, and these give a more complete picture of the privileges of occurrence of the items that form the focus of this section.

The data in (23) illustrate the fact that the adjectives under consideration agree with their DPs, as well as the fact that they can both precede and follow the latter. The fact that they are DP-external is extremely clear in pre-DP position, since they precede the definite article in French and do not host the enclitic definite article in Romanian, as DP-initial adjectives do. To illustrate the last point, observe that in (24a), which is not a type-(III) construction, it is the first of the two prenominal adjectives that hosts the enclitic, while in (24b), which is a type-(III) construction, the enclitic is hosted by the second adjective.

(24) a. Interesant-a noua idee a reginei.... interesting-the new idea of queen-the 'The interesting new idea of the queen...'

b. Singura nobil-a noastra regina ... alone noble-the our queen 
'Only our noble queen ...'

DP-external status can also be demonstrated with post-DP adjectives. Thus, in French and Romanian, DP-internal post-nominal 'ordinary' adjectives may either precede or follow a complement of $\mathrm{N}$, depending on its 'heaviness'; i.e., the adjective needs to be quite heavy in order to follow the complement, as illustrated in (25)-(26).

(25) a. La secretaire intelligente du roi... the secretary-F intelligent-F of-the king 'The king's intelligent secretary...'

b. *La secretaire du roi intelligente...

c. La secretaire du roi si belle et intelligente... the secretary-F of-the king so beautiful-F and intelligent-F

(26) a. Secretara inteligenta a regelui... secretary-the-F intelligent-F of king-the-Gen 'The king's intelligent secretary...'

b. *Secretara regelui inteligenta...

c. Secretara regelui atat de frumoasasi inteligenta... secretary-the-F king-the-GEN so beautiful-F and intelligent-F

In contrast, the kind of adjectives under consideration here can absolutely not occur immediately before a post-nominal $\mathrm{N}$-complement, but can occur after such a complement (subject to certain conditions; see below). (27a) and (28a) demonstrate that the only possible reading that emanates from these sentences is the irrelevant non-quantificational reading:

a. La fille seule du roi peut encore nous aider. the daughter alone of-the king can still us help 'The unaccompanied daughter of the king can still help us.'

b. ?La fille du roi seule peut encore nous aider. the daughter of-the king alone can still us help 'Only the king's daughter can still help us.'

(28) a. Fiica singura a regelui ne mai poate ajuta. daughter-the alone of king-the-GEN us still can help 'The unaccompanied daughter of the king can still help us.'

b. ?Fiica regelui singura ne mai poate ajuta. daughter-the king-the-GEN alone us still can help 'Only the king's daughter can still help us.'

Having argued for the DP-external position of the adjective and having touched on matters of relative heaviness, we wish to show that comparable considerations of relative heaviness play an important role in determining the acceptability of A+DP and DP+A 
constructions. This is not immediately apparent in (23), where A and DP are presumably balanced for heaviness, but becomes detectable in data like (27b) and (28b), which are only acceptable if the boldfaced item is intonationally separated from the preceding DP and carries relatively heavy stress (two factors that are usually taken to contribute to 'heaviness'); in contrast, if the order of DP and A is reversed, acceptability is straightforward and unproblematic. Importantly, if the length and complexity of DP is increased to a sufficient degree, stress and intonational insulation of $\mathrm{A}$ are no longer sufficient to salvage the construction, as illustrated below:

(29) a. *La fille aînée de notre noble roi seule peut encore nous sauver. the daughter eldest of our noble king alone-F can still us save

b. *Fica cea mare a nobilului nostru rege singura ne mai daughter the eldest of noble-GEN our king alone-F us still poate salva.

can save

'Only the eldest daughter of our noble king can still save us.'

Hard to pin down as the notion 'heaviness' may be, it has sometimes been noted that nonreferential nominals (in particular, indefinite ones) count as 'heavier' than referential ones (Postal, 1974). In keeping with this observation, the order A+DP is preferred when DP is indefinite:

(30) a. \{Seul un miracle / ?*un miracle seul $\}$ peut encore nous sauver. alone a miracle a miracle alone can still us save

b. \{Singura o minune / ?*o minune singura $\}$ ne mai poate salva. alone a miracle a miracle alone us still can save

'Only a miracle can still save us.'

Finally, definite personal pronouns, which generally count as quite 'light', are usually unacceptable in the order A+DP:

(31) a. \{Elle seule / *seule elle\} peut encore nous sauver. she alone alone she can still us save

b. $\{\mathrm{Ea}$ singura / *singura ea $\}$ ne mai poate salva. she alone alone she us still can save

'Only she can still save us.'

Nonetheless, as Georges Rebuschi (p.c.) pointed out to us, the deviant versions of (31) become acceptable is the pronoun is heavily stressed and used deictically, i.e., accompanied by a pointing gesture (something that arguably turns it into a proper name). -- In short, to the extent that the notion 'heaviness' is understood, the acceptability of A+DP vs. DP+A orders is determined to a significant extent by relative 'heaviness.' 
A further property of the construction under consideration that takes us closer to proposing an analysis is that the adjective, just like the homonymous items of constructions of type (I), resist modification even by items that make conceivable semantic sense. Thus, the French and Romanian items tout and complet respectively, which function essentially like the English item all in she was all alone in the room, are completely impossible in (23), (27)-(28) and (30)-(31). On this basis, we propose that the operator adjectives of type(III) constructions are functional heads, much like those of type-(I) constructions.

The similarity between the adjectives of type-(I) and type-(III) constructions goes in fact one step further: both belong to the nominal extended projection (although, of course, to different 'levels' of that projection). Thus, in contrast to the categorial 'promiscuity' of the particles of type-(II) constructions, the adjectives of type-(III) constructions seem to attach to DPs only. We illustrate this contrast between type-(II) and type-(III) operators with respect to predicative nominals, which are NPs, not DPs.
a. Jean est $\{$ seulement/ *seul $\} \quad$ ouvrier. Jean is only alone-M-SG worker
b. Ion e \{numai / *singur muncitor.
Ion is only alone-M-SG worker
'John is only a manual worker.'

We are now ready to propose a structure for type-(III) constructions. We submit that these differ minimally from type-(I) constructions in that the functional projection headed by the adjective is below DP in the latter and above DP in the former; this is schematically shown in (11) (reproduced below) and (33) respectively.

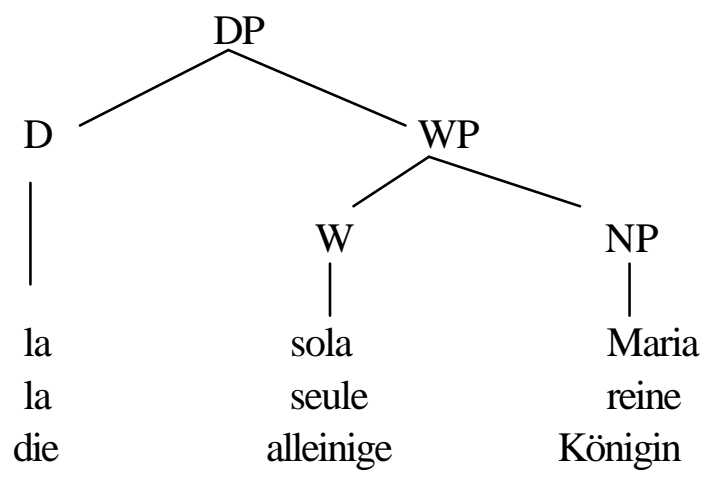

(33)

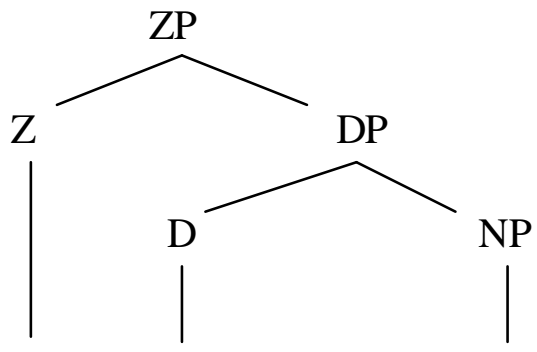




$\begin{array}{ccc}\text { seule } & \text { la } & \text { reine } \\ \text { singura } & -\mathrm{a} & \text { regin- }\end{array}$

We have used different labels for the two functional categories because the items that head them exhibit, despite many similarities, also some important differences. After noting one further similarity, we turn to the differences.

Since both Ws and Zs exhibit the same adjectival morphology and inflectional properties, we see no reason to assume a difference in their interpretable categorial features. Furthermore, in order to capture the fact that both are members of the nominal extended projection, we need to extend to $\mathrm{Z}$ the kind of assumption we proposed to make about $\mathrm{W}$ in section 2.2.: that $\mathrm{Z}$ includes an uninterpretable $\mathrm{N}$-feature (or D-feature) which forces the interpretable categorial feature of $\mathrm{N}$ that has covertly reached $\mathrm{D}$ to further raise to $\mathrm{Z}$. We will not consider in detail the mechanisms that ensure morphological agreement within the nominal extended projection (see footnote 2), but it seems to us that whatever mechanisms are responsible for agreement in (11) can also be assumed to be operative in (33).

Having outlined a number of properties shared by $\mathrm{W}$ and $\mathrm{Z}$, we now address the difference alluded to two paragraphs earlier, and which concerns the distributional privileges of WPs and ZPs. Whereas the former can occur in overt representations both in positions that do and in positions that do not have scope over the clause's CFC, as can be seen by examining (7), (8) and (13), the latter are only felicitous in positions that do have such scope. We proceed to support this claim.

In addition to the pre-verbal subject position, type-(III) constructions may occur in cleftfocus position and in the 'topic' position of 'complex inversion' constructions, as illustrated in (34)-(35). In view of the fact that Romanian does not have such constructions, we are forced to limit our illustrations to French. ${ }^{10}$

(34) a. C'est \{seule la directrice du conseil d'administration, it is alone the directress of-the council of-administration la reine seule \} qui estencore en mesure de nous aider. the queen alone who is still in measure of us help 'It is \{only the directress of the administrative council, the queen only\} who is still in a position to help us.'

b. C'est \{seul un ami de son fils, son fils seul $\}$ que le roi it is alone a friend of his son his son alone that the king est encore pret a recevoir. is still ready to receive 'It is \{only a friend of his son, his son only that the king is still willing to see.' 
(35) \{Seule la reine, la reine seule\} est-elle encore capable de nous aider? alone the queen the queen alone is-she still capable of us help 'Is it only the queen who can still help us?'

In contrast, type-(III) constructions may not function as post-verbal subjects, direct objects, P-objects/verbal PP complements, and foci of pseudo-cleft constructions, as illustrated in (36)-(39) respectively.

(36) a. Le palais où réside $\left\{\left({ }^{*}\right.\right.$ seule $)$ la reine, la reine $(*$ seule $\left.)\right\} \ldots$ the palace where lives alone the queen the queen alone

b. Palatul in care locuieste $\left\{\left({ }^{*}\right.\right.$ singura $)$ regina, palace-the in which lives alone queen-the

regina $\quad(*$ singura $)\} \ldots$

queen-the alone

'The palace in which only the queen lives...'

(37) a. Le roi est prêt a recevoir $\left\{\left({ }^{*}\right.\right.$ seul $)$ un ami de son fils, the king is ready to receive alone a friend of his son son fils (*seul) $\}$

his son alone

b. Regele e gata sa primeasca $\left\{\left({ }^{*}\right.\right.$ singur $)$ un prieten al fiului king-the $i$ ready SUBJ receive alone a friend of son-the-GEN sau, pe fiul lui (*singur)\}.

his ACC son-the his alone

'The king is willing to see \{only a friend of his son's, his son only\}.'

(38) a. J'ai envoyé cette lettre $\left\{\left({ }^{*}\right.\right.$ seule $)$ à notre reine, à (*seule $)$ notre reine, I have sent this letter alone to our queento alone our queen à notre reine (*seule)\}.

to our queen alone

'I sent this letter (only) to the queen.'

b. M-am uitat \{(*singura) la regina noastra, la (*singura) me-have-I looked alone at queen-the our at alone regina noastra, la regina nostra (*singura) $)$. queen-the our at queen-the our alone 'I looked (only) at our queen.'

(39) a. Ce que je reussis a voir est (\{seulement, *seule $\})$ that which I manage to see is only alone la surface du lac $\left({ }^{*}\right.$ seule $\left.)\right\}$.

the surface of-the lake alone

b. Ceeace reusesc sa vad e (\{numai, *singura $\}$ ) 


that-which manage-I SUBJ see is only alone
suprafata lacului (*singura).
surface-the lake-the-GEN alone
'What I manage to see is just the surface of the lake.'

Particularly significant are the facts that (34b), which is the cleft version of the unacceptable full versions of (37a), is acceptable, and that ZPs in pseudo-cleft focus position (which, unlike the cleft focus position, is not a CFC-scope position) are unacceptable. -- In short, the contrast between (23) and (34)-(35) on the one hand and (36)-(39) on the other unmistakeably points to the generalization that ZPs need to have scope over the clause's CFC in overt representation. More carefully put, ZP's need to occur in positions where 'tampering' with their chain (see step (iii) of section 2.2.), if necessary, enables Z to take CFC-scope. ${ }^{11}$ The boldfaced qualification is motivated by the existence of acceptable constructions in which $\mathrm{Z}$ and DP are discontinuous in overt representation, and in which $\mathrm{Z}$ has CFC-scope: ${ }^{12}$

(40) a. La reine a seule l'autorité de dissoudre le parlement. the queen has alone the authority of dissolve the parliament 'Only the queen has the right to dissolve the parliament.'

b. ?La reine peut seule nous aider dans cette situation difficile. the queen can alone us help in this situation difficult 'Only the queen can still help us in this difficult situation.'

(41) a. Regina are singura dreptul sa dizolve parlamentul. queen-the has alone right-the SUBJ-PRT dissolve parliament-the 'Only the queen has the right to dissolve the parliament.'
b. ?Regina mai poate singura sa ne ajute. ${ }^{11}$ queen-the still can alone SUBJ-PRT us help 'Only the queen can still help us.'

(42) a. Seule peut encore nous sauver notre grande et noble reine. alone can still us save our great and noble queen

b. Singura ne mai poate salva marea si nobila noastra regina. alone us still can save great-the and noble-the our queen 'Only our great and noble queen can still save us,'

The discontinuities in (40)-(41) arise due to the combined effect of overt V-Raising out of VP and DP-Raising out of ZP, stranding Z in SpecVP. The discontinuity in (42) is arguably due to a stylistic process that postposes DP out of ZP. We note that (42) is distinct from the more usual French/Romanian data with post-verbal subjects, such as (36), because, in contrast to the latter, $(42 \mathrm{a}-\mathrm{b})$ belong to a very elevated stylistic register, and the post-verbal 
subject must moreover be quite 'heavy' and intonationally insulated from the preceding context.

The distributional restrictions on ZPs we have just noted are straightforwardly accounted for is we assume that the operator features of $\mathrm{ZP}$, in contrast to those of constructions of type (I) and (II), are unable to undergo QR, for some reason. On the background of our account of data of type (1a) and (1b) there is a natural solution. Recall that (1a), La sola Maria si e presentata, is licit because $\mathrm{FF}$ (sol-) can travel to the top node of DP, and since DP is presumably in a proper scope position by virtue of being in subject position, the operator feature corresponding to sola is licensed. Were the DP in question in a non-subject position, it would have to undergo covert movement in the sense of QR. In (1b), Only Mary showed up, the particle was said to be a head which turns the whole phrase into a certain semantic entity (essentially a quantified phrase), while being syntactically inert. Since, according to our assumptions, only does not have a syntactic feature that could project, it is the DP which projects. Again, if this DP is in subject position, the particle has scope over a CFC. If it is not, [XP only XP] has to undergo covert movement to SpecPrtP essentially identifying the head of PrtP. Consider now (1c), \{Singura Maria, Maria singura\} s-a prezentat, and assume the DP in it is a ZP of the kind shown in (33). What is this ZP like? It consists of a head, singura, which is an inflected adjective, and a DP which agrees with it at least in gender and number. In terms of bare phrase structure, it differs in one important way from [DP only DP]: It is headed by AGR. With respect to checking, it also differs in one important way from [DP D [sol-AGR NP]: The DP-external agreeing head must have a Dfeature which attracts and is checked either overtly by the complement DP or covertly by FF(DP). These two options which we will not explore in more detail are attested by the two basic orderings between the external operator and the DP. The DP-internal agreeing +operator adjective (or its AGR-part), on the other hand, must have an $\mathrm{N}$-feature which attracts $\mathrm{FF}(\mathrm{NP})$. Consider now (11) and (33) which we repeat here for convenience:
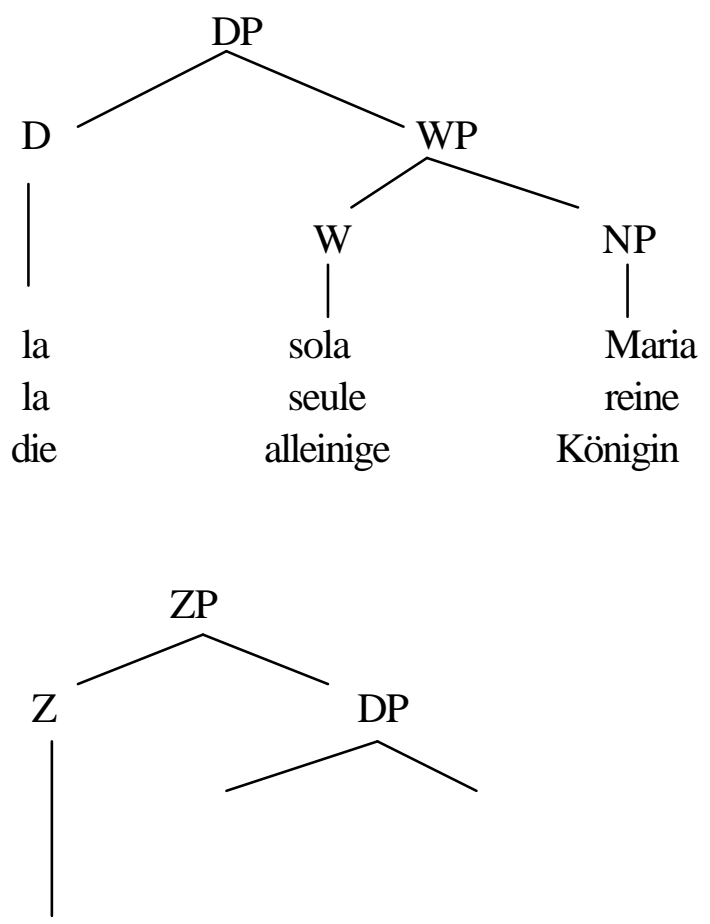
$\begin{array}{ccc} & \text { D } & \text { NP } \\ & \mid & \mid \\ \text { seule } & \text { la } & \text { reine } \\ \text { singura } & -\mathrm{a} & \text { regin- }\end{array}$

In both cases, we view Move-F as a semantically blind morphological process. In (11), $\mathrm{FF}(\mathrm{NP})$ raise to $\mathrm{W}$, and $\mathrm{FF}(\mathrm{WP})$ raise to $\mathrm{D}$. Both processes are driven by the need to check the respective head's N-feature as encoded in the AGR(eement) of D. In the second process, the +op feature of sol- gets a free ride to $\mathrm{D}$, and will, as a consequence, be present at the DP-node. In (33), FF(DP) raise to Z, -- unless DP raises overtly, which also gives an attested result as we have seen. In either case, $Z$ has a D-feature which is checked off by FF(DP). Assume now that in order to undergo QR, XP must be such that its head bears the top feature. The two familiar cases are the type-(II) construction and the type-(I) construction: The relevant head in (II) is Prt. The relevant head in (I) is a derived feature complex that appears in the functional categories D or P. Construction (III), as shown in (33), differs from both of these cases because Z, seule/singura, is strictly speaking not a functional head. Its functional part is AGR. Checking this featural complex by raising of FF(DP) will not have the required semantic effect because now AGR will disappear without +op becoming a feature of the formal head of the phrase. We think that it is precisely this lack of formal marking which disables ZP to undergo semantically motivated movement to a pre-VP scope position. Notice now that seule/singura does contain +op albeit not as its formal head. If ZP has moved to the canonical pre-VP subject position as in (23), (30), (31) or if $\mathrm{Z}$ has been stranded in such a position as in (40)-(42), and if this position is sufficiently "high" to enable +op to take scope over the CFC VP, then QR becomes unnecessary. The scope requirement is accidentally met because of ZP's appearance in subject position. What about clefting and complex inversion as exemplified in (34) and (35) respectively? All we can say at this moment is that any account of these constructions in French will have to guarantee that +op is ultimately copied into a position higher than VP. To summarize, our account of the pre-/post-V asymmetry observed in connection with the type-(III) construction rests on the idea that QR presupposes formal marking of XP with +op, and that under close scrutiny such formal marking is absent in ZP. ${ }^{13}$ It follows that those ZPs which enable +op to take scope must have moved to a scope position by a process that is independent of the motivations underlying QR.

Before concluding, we will take a look at some data of English and German that we briefly alluded to at the beginning of this section. The data, which are illustrated in (44), share superficial properties with both type-(II) and type-(III) constructions.

(44) a. \{The queen alone, *alone the queen $\}$ can still help us. ${ }^{14}$

b. \{Die Königin allein, allein die Königin\} kann uns noch helfen. the queen alone alone the queen can us still help 
Just like the operator elements of type-(III) constructions, the boldfaced elements in (44) are homonymous with items that mean 'unaccompanied' or 'unaided.' On the other hand, these elements are uninflected, just like the particles of type-(II) constructions. The latter property is not significant for English, where adjectives are always uninflected, but it is potentially significant for German, where adnominal adjectives are inflected. To see whether the constructions in (44) are of type (II) or (III), we need to check their distributional privileges in post-verbal contexts. The following data show that they are allowed in such contexts, and thus point to the conclusion that they are of type (II).

(45) a. This proposal concerns the queen alone.

b. This remark was meant for you alone.

(46) a. Dies interessiert \{die Königin allein, allein die Königin\}.

this concerns the queenalone alone the queen

b. Ich habe dieses Buch \{der Königin allein, allein der Königin\}

I have this book the-DAT queen alone alone the-DAT queen

gezeigt

shown

'I have shown this book to the queen alone.'

c. Dies war \{für die Königin allein, allein für die Königin\} bestimmt.

this was for the queen alone alone for the queen meant

'This was meant for the queen alone.'

\section{Summary of results}

In this paper, we have addressed three syntactic constructions with comparable semantic import, but with distinct distributional properties and distinct cross-linguistic privileges of occurrence. The constructions (I)-(II), which were discussed at some length in Bayer (1996), have been partly reanalyzed here; construction (III) has been -- to the best of our knowledge -- neither described nor analyzed in the earlier generative literature. We have proposed to analyze their intra-linguistic and cross-linguistic distributional properties in terms of differences in the featural make-up of lexical items with operator import that individual languages may or may not have. In particular, we proposed that in constructions of type-(I) the operator's features may percolate up the phrase marker as a consequence of purely formal and non-semantic checking operations. Constructions of type-(II) have only operator features, and that these are forced to undergo movement to a scope position unless such movement is blocked by known constraints on Move-a. Type-(III) constructions reveal an asymmetry between pre- and postverbal position by virtue of the fact that their operator feature is not formally represented in a way that would permit QR-style movement to a scope position. A semantically well-formed structure can only be achieved in those cases 
where the relevant phrase is already in a potential scope position for reasons that have nothing to do with semantics proper.

In analyzing these various constructions, we pointed to the need to recognize two types of covert movement operations, one purely formal and one semantics-oriented. The present results support conclusions about two types of covert movement that were reached in Bayer (1996; 1998; 1999), but they clearly go beyond that in presenting a more fine-grained picture of the interaction between the syntax of inflectional morphology and semantic interpretation. In doing so we have shown that important insights from both the Criterion approach by Rizzi $(1991 ; 1997)$ and the feature-checking approach of Chomsky (1995) can be successfully integrated into a more unified account.

\section{FOOT NOTES}

[1] See Bech (1955/57: 76ff), who seems to have been the first to propose that negative elements like German kein are in fact 'cohesive' forms of negation and the indefinite determiner ein. On this point, see also von Stechow \& Geuder (ms.) and Landman (ms.).

[2] We have constructed our account in terms of the categorial feature of the noun because Chomsky (1995) considers that categorial features are interpretable, and thus undeletable, in contrast to say, Case features, which he views as uninterpretable. The view that categorial features are interpretable is not unchallengeable, but not unreasonable, either (we note that various formal semantic theories posit a tight correlation between syntactic categories and logical types).

Note that the covert raising of formal features does not obviously account for morphological agreement within DP, since at least some of the agreeing features are viewed as uninterpretable (e.g., Gender and Case), and if they take part in usual checking operations as the $\mathrm{N}$-feature raises from head to head, the uninterpretable features would be deleted too soon. We leave open the treatment of morphological agreement within DP.

[3] Szabolsci (1995) points out that in data with subject quantified phrases, the Beghelli \& Stowell hypothesis would seem to assume an 'improper chain', that is, one in which movement to an A'-position is followed by movement to an A-position, on the assumption that the specifiers of such phrases as Beghelli \& Stowell's Dist(ributive)P or our PrtP probably are A'-positions.

The force of this objection is unclear to us. First, the notion 'A-position' is far harder to characterize on independent grounds within a model that assumes functional categories than in the LGB model, since such positions as [Spec, TP] are clearly not argument positions in 
the LGB sense of '(potential) theta-positions.' We thus see no conceptual problems with assuming that SpecPrtP is an A-position. Second, the kind of reasons that exclude 'classical' improper chains, as in (i), do not apply here.

(i) a. It was asked by John [who had seen Mary].

b. *Who was asked by John [ $\mathrm{t}$ had seen Mary].

In (ib), instead of inserting a dummy in the [-theta] position in the matrix subject position, as in (ia), who has raised from SpecCP, an unquestionable A'-position, to the matrix subject position. Since who has 'used up' its Case feature within the lower clause, it cannot check the matrix Case feature. This situation does not arise in cases like (6), where movement is confined to a single verbal extended projection. In short, we see nothing obviously 'improper' about the chain that the Beghelli \& Stowell approach would assume with respect to the examples in (7).

[4] To illustrate, Ross (1967) simply stipulated that PPs are in fact NPs. Moritz \& Valois (1994) proposed covert movement of DP to SpecPP, an operation that is somewhat suspicious for French (the language they studied), since it is never overtly attested. Various other proposals could be adduced.

[5] Kayne (1998) denies the need for covert movement even in such cases. This result is purchased at the cost of a large number of overt movements. For space reasons, we refrain from discussing the implications of his proposal here.

[6] Owing to a strange and ill-understood requirement of Romanian grammar, regina is - in fact, must be -- construed as definite despite the absence of the enclitic definite article. By and large, if the complement of a $\mathrm{P}$ consists of a single word, in particular, a noun, the enclitic is morphologically suppressed and semantically 'understood.' If the complement of $\mathrm{P}$ consists of more than one word and the enclitic can in principle occur, a definite reading is obtained, only if the enclitic is morphologically present. This phenomenon is not found with all prepositions; for example, $\mathrm{cu}$ 'with' constitutes an exception.

[7] See also Ross \& Cooper (1979) for relevant judgments.

[8] We will not consider here examples in which only takes scope over non-propositional domains, as, for example, in (i) and (ii), where only functions as a 'scalar' operator.

(i) John could see only THREE/FEW of the soldiers.

(ii) The relatives of only THREE/FEW soldiers showed up.

For discussion and for a proposal on how to unify the quantificational and scalar uses of only, see Bayer (1996: ch.2).

[9] See, for instance, Guéron \& May (1984) and May (1985: ch.4) on extraposed result clauses with so:

(i) a. *I told her 1 that the concert was attended by many people last year who made Mary ${ }_{1}$ nervous

b. I told her ${ }_{1}$ that the concert was attended by so many people last year that I made Mary 1 nervous

See also the discussion of antecedent-contained deletion, especially conclusions about the construction's status in the context of Minimalism (see Kennedy, 1997: 684ff). 
[10] We have used 'heavier' DPs with the order A+DP because data like (i) are unacceptable.

(i) *C'est seule la reine qui peut encore nous sauver.

We conjecture that the focus position of clefts, which is an automatic stress position, is more sensitive to relative 'heaviness' than normal argument positions, and also that seule is presumably somewhat heavier than la reine. This distinction seems not to be significant enough to block the A+DP order in data like those in (23).

[11] The kind of 'tampering' that takes place in cleft constructions like (34) depends on one's analysis of clefts. If the focus phrase is reordered from within IP, as proposed, for example, in Kayne (1994), we have a straightforward chain, and tampering has its usual sense. If the focus phrase is base-generated in its surface position, as proposed, for example, in Chomsky (1977), some extension of the notion 'chain' appears to be needed. In any event, some form of 'reconstruction' is certainly needed in clefts in general and in data like (i) in particular.

(i) C' estseule une photo de lui-memeque le roi serait

it is only a picture of himself that the king would-be

pret a accepter

ready to accept

To satisfy Condition A of the Binding Theory, une photo de lui-meme must be reconstructed in the position of object of accepter, while seule needs to retain its surface position under a base-generated analysis, or undergo reconstruction to a position that has CFC-scope under a movement analysis.

[12] The difference between the a.- and b.-examples in (40) and (41) seems to rest on the fact that meaningful verbal elements need to be within the scope of the operator in overt representation. Thus, main verbs can certainly raise overtly in French and Romanian (Pollock 1989), but if they raise to the left of the operator in constructions like (23)-(24), the result is degraded, e.g.:

(i) ?*La reine boit seule du Dom Pérignon.

the queen drinks alone some Dom Pérignon

'Only the queen drinks Dom Pérignon.'

(ii) ?* Regina bea singur| Mampanie de calitate. queen-the drinks alone champaign of quality

'Only the queen drinks high quality champaign.'

The (b) sentences in (40)-(41) are thus arguably somewhat harder to accept than the (a) sentences because modals have more content than the verbs be/have.

[13] Claiming that +op is missing in the formal syntactic representation of (33) and that this fact prevents $\mathrm{ZP}$ from undergoing $\mathrm{QR}$ does not imply that top is the only trigger for $\mathrm{QR}$. As we pointed out already, there are reasons to believe that $\mathrm{QR}$ can also apply to XPs which are not quantified in the narrow sense. What is at issue here, however, is the fact that $\mathrm{ZP}$ will fail to activate a PrtP because formally it does not amount to more than a DP.

[14] In section 3, we proposed that the unspecified categorial FFs of operator particles that can both precede and follow XP need to be allowed to be either strong or weak. The 
English operator particle alone has necessarily strong unspecified features, since it is only allowed in post-XP position.

\section{Acknowledgements}

We would like to thank the following colleagues who helped us at various stages with theoretical as well as with data-oriented discussion: Anna Cardinaletti, Norbert Corver, Carmen Dobrovie-Sorin, Marc-Ariel Friedemann, David Gaatone, Julia Horvath, Giuseppe Longobardi, Virginia Motapanyane and Georges Rebuschi. Thanks also to the audiences of the 1998 Incontro di Grammatica Generativa in Verona and the 1998 Generative Grammatik im Süden at Salzburg where parts of this research were presented.

\section{B I B L I O G R A P H Y}

Bayer, Josef (1996) Directionality and Logical Form. On the Scope of Focusing Particles and Wh-in-situ. Kluwer: Dordrecht.

Bayer, Josef (1998) Two types of covert movement. Paper presented at the Workshop on acquisition and variation in syntax and semantics, Trieste, SISSA.

Bayer, Josef (1999), Bound focus or: How can association with focus be achieved without going semantically astray? In: Rebuschi, Georges \& Laurie Tuller (eds.), The Grammar of Focus. Benjamins: Amsterdam.

Bech, Gunnar (1955/57) Studien Ueber das deutsche Verbun infinitum. Copenhagen. Reprinted 1981 by Niemeyer: Tübingen.

Beghelli, Filippo \& Tim Stowell (1995), Distributivity and negation. In: Szabolsci, Anna (ed.), Ways of Scope Taking. Kluwer: Dordrecht.

Brody, Michael (1998), Projection and phrase structure, Linguistic Inquiry 29, 367-398.

Chomsky, Noam (1977), On wh-movement. In: Culicover, Peter, Thomas Wasow \& Adrian Akmajian (eds.), Formal Syntax. Academic Press: New York. 
Chomsky, Noam (1986), Knowledge of Language. Praeger: New York.

Chomsky, Noam (1993). A minimalist program for linguistic theory. In: Hale, Kenneth \& Samuel Jay Keyser (eds.), The View from Building 20. The MIT Press: Cambridge, Mass.

Chomsky, Noam (1995) The Minimalist Program. The MIT Press: Cambridge, Mass.

Cinque, Guglilemo (1993), On the evidence for partial N-Movement in the Romance DP. University of Venice Working Papers in Linguistics vol. 3, No. 2.

Davison, Alice (1988), Operator Binding, Gaps and Pronouns, Linguistics 26, 181-214.

Fox, Danny (1994), Quantifier scope and VP-ellipsis. Ms., MIT.

Fox, Danny (1995), Economy and scope. Natural Language Semantics 3, 283-341.

Gallmann, (1996) Die Steuerung der Flexion in der DP, Linguistische Berichte 164, 283314.

Gallmann, (1997) Zur Morphosyntax und Lexik der wWörter. Arbeitspapier \#107 des SFB 340 Sprachtheoretische Grundlagen für die Computerlinguistik. Stuttgart Tübingen.

Gorrell, Paul (1987) Studies of Human Syntactic Processing: Ranked Parallel versus Serial Models. Ph.D. Dissertation, The university of Connecticut, Storrs, Connecticut.

Grimshaw, Jane (1991) Extended Projection. Ms., Brandeis University.

Grosu, Alexander (1994) Three Studies in Locality and Case. Routledge: London and New York.

Guéron, Jacqueline \& Robert May (1984) Extraposition and Logical Form, Linguistic Inquiry 15, 1-31.

Haider, Hubert (1993. Deutsche Syntax - generativ: Vorstudien zur Theorie einer Projektiven Grammatik. Narr: Tübingen.

Hornstein, Norbert (1995) Logical Form. From GB to Minimalism. Blackwell: Oxford, UK \& Cambridge, USA.

Kayne, Richard (1994) Antisymmetry in Syntax. The MIT Press: Cambridge, Mass. 
Kayne, Richard (1998), Overt versus covert movement, Syntax: A Journal of Theoretical, Experimental and Interdisciplinary Research 1, 128-191.

Kennedy, Christopher (1997), Antecedent-contained deletion and the syntax of quantification, Linguistic Inquiry 28, 662-688.

Kiss, Katalin É. (1991), Logical structure in syntactic structure: The case of Hungarian. In: Huang, C.-T. James \& Robert May (eds.), Logical Structure and Linguistic Structure. Kluwer: Dordrecht.

Koster, Jan (1987) Domains and Dynasties: The Radical Autonomy of Syntax. Foris: Dordrecht.

Lappin, Shalom (1991) Concepts of logical form in linguistics and philosophy. In: Kasher, Asa (ed.), The Chomskyan Turn. Blackwell: Oxford, UK \& Cambridge, USA. 300-333.

Larson, Richard (1988) On the double object construction. Linguistic Inquiry 19, 335391.

May, Robert (1977) The Grammar of Quantification. Ph.D. dissertation, MIT.

May, Robert (1985) Logical Form: Its Structure and Derivation. The MIT Press: Cambridge, Mass.

Moritz, Luc \& Daniel Valois (1994) Pied-Piping and Specifier-Head agremeent. Linguistic Inquiry 25, 667-707.

Pollock, Jean-Yves (1989) Verb movement, Universal Grammar, and the structure of IP. Linguistic Inquiry 20, 365-424.

Postal, Paul (1974) On Raising. The MIT Press: Cambridge, Mass.

Reinhart, Tanya (1991) Elliptic Conjunctions -- Non-Quantificational LF. In: Kasher, Asa (ed.), The Chomskyan Turn. Blackwell: Oxford, UK \& Cambridge, USA. 360-384.

Reinhart, Tanya (1993), WH-in-situ in the framework of the Minimalist Program. OTS Working Papers, Utrecht University (published in 1998 in Natural Language Semantics 6. 29-56).

Reinhart, Tanya (1997) Quantifier scope: How labor is divided between QR and Choice Functions. Linguistics and Philosophy 20, 335-397. 
Rizzi, Luigi (1991) Residual Verb Second and the Wh-Criterion. Technical Reports in Formal and Computational Lingustics 2, University of Geneva.

Rizzi, Luigi (1997) The fine structure of the left periphery. In Haegemann, Liliane (ed.), Elements of Grammar. A Handbook in Generative Syntax. Kluwer: Dordrecht.

Rooth, Mats (1985) Association with Focus. Ph.D. Dissertation, University of Mass. at Amherst.

Ross, John Robert (1967) Constraints on Variables in Syntax. Ph.D. thesis, MIT (published in 1984 as Infinite Syntax).

Ross, John Robert (1974) Excerpts from Constraints on Variables in Syntax. In Harman, Gilbert (ed.), On Noam Chomsky: Critical Essays. Anchor Press, Garden City, New York.

Ross, John Robert \& William Cooper (1979) Like Syntax. In Cooper, W.E. \& C.T.Walker (eds.), Sentence Processing: Psycholinguistic Studies Presented to Honor Merill Garett. Lawrence Erlbaum: Hillsdale, New Jersey.

Rothstein, Susan (1991), Heads, Projections, and Category Determination. In: Leffel, K. \& D. Bouchard (eds.) Views on Phrase Structure. Kluwer: Dordrecht.

Safir, Kenneth (1986) Relative Clauses in a Theory of Binding and Levels. Linguistic Inquiry 17, 663-690.

Stechow, Arnim von \& Willi Geuder (1997) Sind manche Sprachen präziser als andere? Über morphologische Kategorien und ihre Interpretation. Ms., Seminar für Sprachwissenschaft, Universität Tübingen.

Szabolsci, Anna (1995). In: Szabolsci, Anna (ed.), Ways of Scope Taking. Kluwer: Dordrecht.

Tsai, Wei-tien Dylan (1994). On Economizing the Theory of A-bar Dependencies, unpublished MIT dissertation, distributed by MIT Working papers in Linguistics, Cambridge, MIT Press. 